\title{
PERFORMANCE OF SMALL HORIZONTAL AXIS AND VERTICAL AXIS SHROUD AUGMENTED WIND TURBINES
}

\author{
Kyriakos Vafiadis \\ Dept. of Mechanical Engineering \\ University of Western Macedonia \\ kvafiadis@uowm.gr \\ Kozani, Greece
}

\author{
Antonios Tourlidakis \\ Dept. of Mechanical Engineering \\ University of Western Macedonia \\ atourlidakis@uowm.gr \\ Kozani, Greece
}

\begin{abstract}
The introduction of a stationary shroud around the rotor is a technology developed to increase the power extraction of small wind turbines. In this context, a horizontal axis wind turbine, a vertical axis wind turbine and corresponding shrouds were designed and the potential of their combination was assessed. A number of Computational Fluid Dynamics simulations were carried out for both the bare and the shrouded rotors and significant results were produced. The analysis showed that the shrouds have a positive effect on the performance of both wind turbine types. A reduced static pressure behind the rotor leads to improved energy extraction from the air flow. Moreover, the addition of a flange at the exit of the shroud was evaluated. The presence of the flange causes further pressure drop at the shroud exit area and at the rotor exit and improves the production of useful mechanical work by the rotor. An increase of the flange size results to improved power extraction. A comparison of the computational results with experimental results of other researchers shows an agreement of the tendencies observed.
\end{abstract}

\section{INTRODUCTION}

Modern wind turbines are designed to maximise their power coefficient which is the ratio of the actual power extracted to the power carried by the wind due to its kinetic energy. The maximum theoretical value of the power coefficient is defined by the Betz limit which, in practice, is impossible to achieve with wind turbines with open rotors. However, since the wind power is proportional to the third power of wind speed, the possibility of exceeding the Betz limit by accelerating the flow has been explored for decades. Shrouded wind turbines have been proposed as an improvement for conventional wind turbines. In this case the shroud has the shape of a diffuser, with a large diffusion angle and in many cases a perforated surface in order to control and activate the growing boundary layers. These wind turbines are characterized as Diffuser Augmented Wind Turbines (DAWT). The definition of performance improvement is the ratio of the power extracted by a shrouded rotor to the power of a similar rotor without a shroud. The first experiments concluded that improving the performance of a rotor depends on the thrust coefficient (rotor loading), the pressure recovery through the diffuser and the exit pressure. These correlations, in turn, are related to the ratio of the shroud exit area to the shroud neck area and the efficiency of the diffuser (Foreman et al., 1978; Igra, 1981; Fletcher, 1981; Gilbert and Foreman, 1983).

In the early 2000s, extensive research was carried out by conducting numerical simulations and experimental studies of the flow in diffuser shaped shrouds for use with small (below $1.5 \mathrm{~kW}$ ) wind turbines (Abe and Ohya, 2004; Abe et al., 2005). The diffusers had exit flanges of different heights (Fig. 1.a). The results of these simulations were verified by experimental results and showed good agreement. The simulations were performed on diffusers with diffusion angles of $4^{\circ}$ to $15^{\circ}$ and it was found that satisfactory flow acceleration is possible to be achieved. Of course, the performance of any diffuser is also related to the flow inside the diffuser and therefore to the rotor thrust coefficient. The flange has a significant importance on diffuser efficiency since it acts as a barrier to the flow around the diffuser, creates a significant detachment of the flow and an extensive recirculation area at its discharge. Thus at the diffuser exit, the pressure is significantly lower than the atmospheric (Fig. 1.b). The flow passing through a flanged diffuser is significantly increased relative to the flow through a diffuser without flange. The maximum speed is observed as expected at the diffuser inlet and hence it is recommended to place in this position the runner which will extract energy from the wind. 
(a)

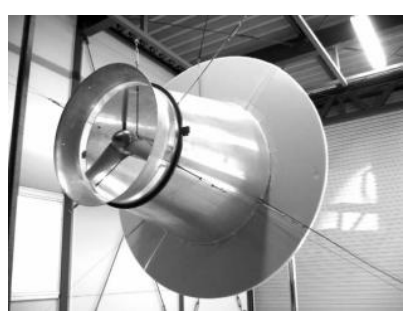

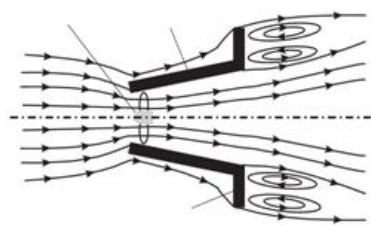

(b)
Figure 1 DAWT with exit flange (Abe et al., 2005): a) The experimental setup b) streamlines through the diffuser

Further work by the same research team and other researchers showed a significant power coefficient improvement that reaches 4-5 times the power of the bare rotor using a shroud (Ohya et al., 2006; Matsushima et al., 2006; Ohya et al., 2008). The diffuser outlet cross section in this case was about twice that of the inlet cross section. In 2010 a device called "Wind-lens" was introduced (Ohya and Karasudani, 2010), which includes a new form of shroud with a smaller diffuser and an exit flange. These devices were developed and tested both experimentally in a wind tunnel and under real conditions in two different sites with the installation of six and three wind turbines, respectively. Each wind turbine had a rated power of $5 \mathrm{~kW}$. The experiments showed that the wind turbine power coefficient was improved 2 to 5 times.

The research on vertical axis wind turbines with shroud is limited and focuses mainly on the "smart" placement of wind turbines in various locations on buildings where flow conditions are favourable (Sharpe and Proven, 2010). Unfortunately, their inclusion in a shroud eliminates the advantage of not requiring a specific orientation. However, shrouds have also been shown to be effective in the case of vertical axis wind turbines (Watson et al., 2007; Abu-ElYazied et al., 2014; Krishnan and Paraschivoiu, 2015; Zanforlin and Letizia, 2015). To preserve the advantage of not requiring a specific orientation and at the same time improve the wind turbine performance, geometries have been studied which are surrounded by devices which are mostly based on a design that is historically first encountered in Persian windmills. The efficiency can be improved by simple shroud designs which are also possible to be building integrated (Müller et al., 2009). A few years later a work which focused on the efficiency improvement of vertical axis wind turbines with an upstream deflector was presented (Kim and Gharib, 2013).

This paper presents the computational results of a study conducted on small rotors of both Horizontal Axis Wind Turbines (HAWTs) and Vertical Axis Wind Turbines (VAWTs). Initially, the rotors were studied using Computational Fluid Dynamics (CFD), in the absence of a shroud, in order to map their performance. Subsequently, analyses were performed in the presence of a shroud to determine the potential improvement on performance.

\section{COMPUTATIONAL STUDY AND RESULTS}

\section{Rotor and Shroud Geometry}

To investigate the effect of a shroud on the performance of the two wind turbine types, the design of a horizontal axis rotor and a vertical axis rotor was selected. For the preliminary rotor performance at the design stage, the QBlade software and the Blade Element Momentum (BEM) along with the Double-Multiple Streamtube (DMS) methods were used. The BEM method is the analysis algorithm for HAWTs while the DMS method is an equivalent method for VAWTs.

The HAWT rotor consists of three blades with a diameter of $1.32 \mathrm{~m}$, hub radius of $0.08 \mathrm{~m}$ and a constant rotational speed of 600rpm. The blades are based on three different airfoil types developed by the National Renewable Energy Laboratory (NREL) for wind turbines with diameter from 1 to $3 \mathrm{~m}$ (Somers, 2005). Figure 2 presents the power coefficient relative to the Tip Speed Ratio (TSR) which is defined as the ratio of the blade tip speed to the wind speed:

$$
\mathrm{TSR}=\frac{2 \pi \Omega R}{60 U}
$$

where $\Omega$ is the rotational speed in rpm, R is the rotor radius (in $\mathrm{m}$ ) and $\mathrm{U}$ is the wind speed (in $\mathrm{m} / \mathrm{s}$ ). As it can be shown with BEM, the performance of the rotor is quite satisfactory for wind speeds in the range of 5 to $10 \mathrm{~m} / \mathrm{s}$, with a maximum power coefficient of around 0.38 , when $\mathrm{U}=8 \mathrm{~m} / \mathrm{s}$ (or $\mathrm{TSR}=4.5$ ).

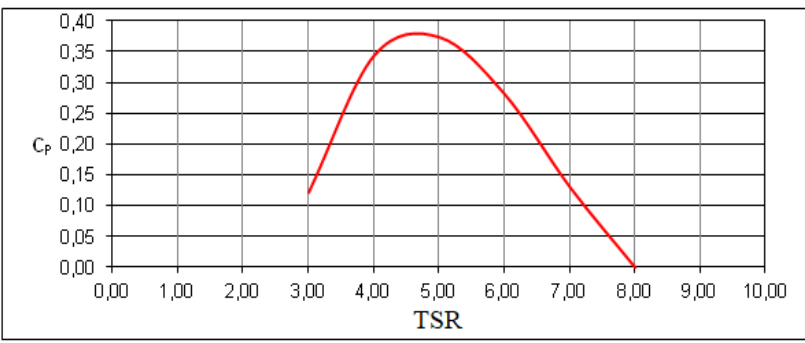

Figure 2 Power coefficient curve

In Table 1 the blade geometry is presented, in terms of the radial distribution of chord length and twist angle together with the type of airfoils used.

Table 1 Blade geometry details

\begin{tabular}{|c|c|c|c|}
\hline$r(\mathrm{~m})$ & $c(\mathrm{~m})$ & $\theta\left(^{\circ}\right)$ & Section airfoil \\
\hline 0.08 & 0.0600 & 0.00 & circle \\
0.10 & 0.0600 & 0.00 & circle \\
0.13 & 0.1300 & 21.82 & NREL S835 \\
0.15 & 0.1273 & 18.34 & NREL S835 \\
0.18 & 0.1150 & 14.30 & NREL S835 \\
0.22 & 0.1058 & 12.37 & NREL S833 \\
0.30 & 0.0804 & 7.53 & NREL S833 \\
0.48 & 0.0532 & 3.01 & NREL S833 \\
0.61 & 0.0465 & 0.34 & NREL S834 \\
\hline
\end{tabular}


The shroud design (Fig. 3) is based on the geometrical configurations of other similar shrouds used by various researchers (Abe and Ohya, 2004; Abe et al., 2005). However, the current design is not exactly the same to these shrouds. The CFD analysis of the shroud was carried out in order to predict the flow behaviour and the effect of placing an exit flange.

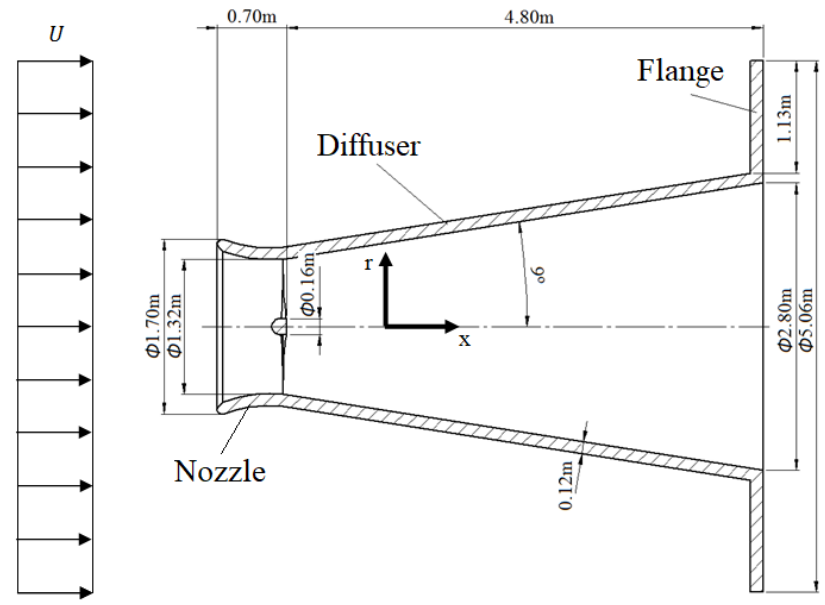

\section{Figure 3 Layout of the turbine - diffuser arrangement}

The VAWT rotor is a simple H-Darrieus design, with a rotor radius equal to $1 \mathrm{~m}$ and height equal to $2 \mathrm{~m}$ (Figure $4 . \mathrm{a}$ ). The rotor consists of three blades based on the symmetric NACA0015 airfoil. The blade chord is $0.28 \mathrm{~m}$ and the rotor solidity is 0.84 . Figure $4 . \mathrm{b}$ presents the top view section of the shroud used. The ratio of outlet to throat area and the ratio of inlet to throat area are both equal to 1.453 .

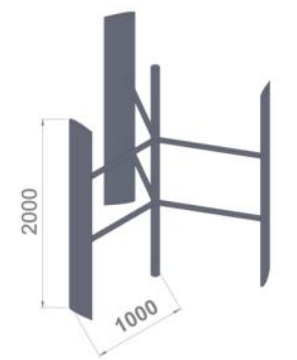

(a)

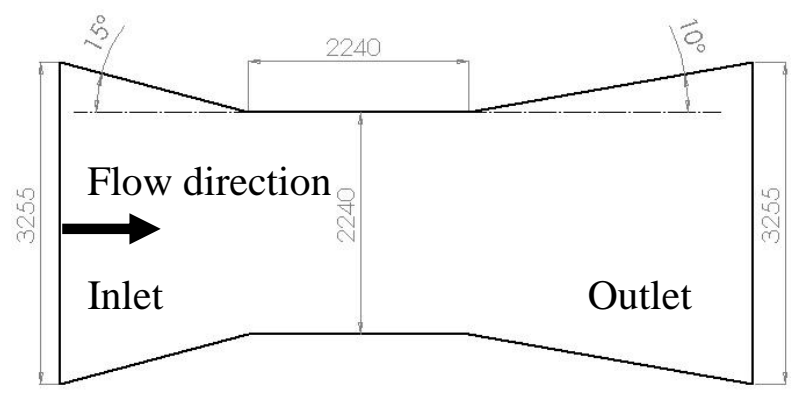

(b)

Figure 4 VAWT model: a) rotor geometry b) top view of the shroud and its dimensions

\section{Numerical model and boundary conditions}

The computational analysis was carried out using the ANSYS CFX commercial software. The governing equations of the flow are the continuity equation and the momentum equations:

$$
\begin{gathered}
\frac{\partial \rho}{\partial \mathrm{t}}+\frac{\partial\left(\rho U_{j}\right)}{\partial \mathrm{x}_{j}}=0 \\
\frac{\partial\left(\rho U_{i}\right)}{\partial \mathrm{t}}+\frac{\partial\left(\rho U_{i} U_{j}\right)}{\partial \mathrm{x}_{j}}=-\frac{\partial p}{\partial x_{i}}+\frac{\partial \tau_{i j}}{\partial x_{j}}+S
\end{gathered}
$$

where: $\rho$ is the density, $U$ is the velocity, $p$ is the static pressure, $\tau$ is the shear stress tensor and $S$ is the source term which includes the Coriolis and centrifugal forces.

The turbulence effects were simulated using the well established k - $\omega$ Shear Stress Transport (SST) turbulence model. This is a two equation eddy viscosity model that accounts for the transport of the turbulent shear stress and gives highly accurate predictions of the onset and the amount of flow separation under adverse pressure gradients. A turbulence kinetic energy production limiter in stagnation points and a curvature correction are applied in order to overcome two common problems of eddy viscosity models. The basic equations of the model for the turbulence kinetic energy and the specific rate of dissipation (of the turbulence kinetic energy into internal thermal energy) are presented in detail in (Menter, 1994).

A steady state analysis approach was adopted for the HAWT simulation. The computational field (Fig. 5.a) consists of two regions, a stationary and a rotating one, which implies the use of different frames of reference. The diffuser is analysed in the stationary frame of reference while the computational disk that includes the rotor lies in the rotating frame of reference. In both regions the fluid is set to be air at a temperature of $25^{\circ} \mathrm{C}$ and the reference pressure is 1 atm.

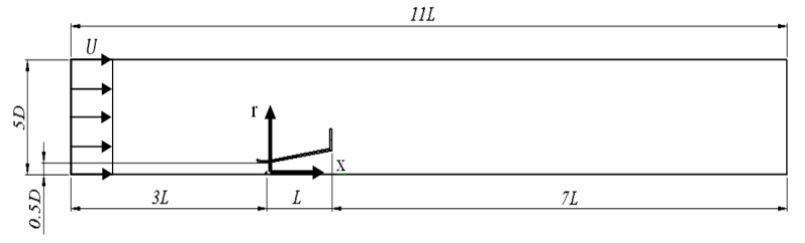

(a)

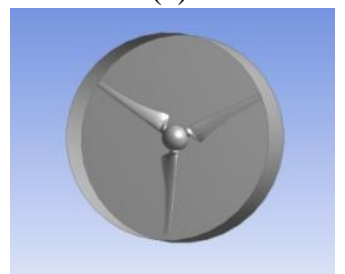

(b)

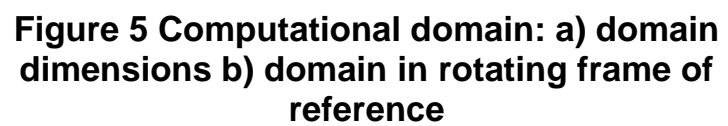

At the interfaces between the stationary and the rotating domains, the Frozen Rotor model was implemented. The 
surfaces of the shroud, the blades and the rotor hub are considered as no slip walls. At the inlet of the computational field the wind velocity was specified and at the outlet a relative static pressure equal to $\mathrm{OPa}$ was set.

For the analysis of the VAWT, due to the complex flow nature which is governed by the rotational movement of the turbine rotor and the interaction of each blade's wake with the other blades, unsteady cases had to be examined. Steady state simulations of every case were examined too. The steady state analyses of the models under examination were carried out in order to obtain a reliable initial condition for the subsequent transient ones. The computational field for the bare rotor case is an orthogonal parallelepiped with a rectangular section. Its height equals to 25 chord lengths, its width is equal to 14 chord lengths and its total length is 46 chord lengths (Fig. 6.a). The computational field for the rotor-shroud configuration case is almost the same but it also includes the shroud and its total length is 54 chord lengths (Fig. 6.b). In both cases, the computational field consists of two regions, a stationary frame of reference region and a rotating frame of reference region. The rotating frame of reference region is a cylinder surrounding the vertical rotor rotating at the rotor rotational speed. At the interface surfaces between the stationary and the rotating domains, sliding interfaces are used and the available "transient rotor-stator" model was implemented. The diffuser's walls, the rotor blades and the rest of the rotor walls are considered as no slip walls. At the inlet of the computational field the wind velocity was fixed at $10 \mathrm{~m} / \mathrm{s}$ and at the outlet a relative static pressure equal to $0 \mathrm{~Pa}$ was applied. The rotor speed was changed for each case and the values 10, 20, 30 and 40 $\mathrm{rad} / \mathrm{sec}$ were examined (these values refer to TSR values equal to 1, 2, 3 and 4 respectively). In order to simulate as many full rotations of the rotor as possible, different time steps were applied, depending on the rotational speed with each time step corresponding to a 10 degrees rotation.

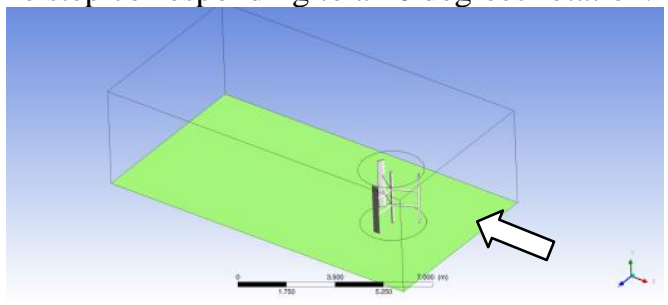

(a)

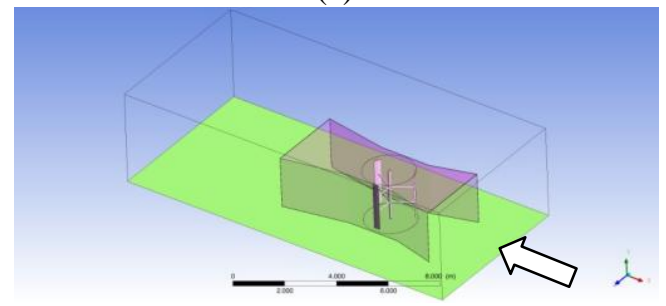

(b)

Figure 6 Computational domain a) bare rotor b) rotor-shroud configuration

The computational grid consists of tetrahedral cells properly refined in regions of curvature and proximity between walls. Since the k- $\omega$ SST model was used to model the turbulence effects along with scalable wall functions the boundary layers on the walls were resolved using fifteen inflation layers, in order to achieve the value of $y^{+}=1$ for the first layer. Initially, a grid independence study was carried out which resulted to the selection of the following grids. The HAWT bare rotor grid consists of about 4.8 million elements while the full arrangement consists of 8.5 million elements. The flanged shroud case consists of almost 10 million elements. The VAWT bare rotor grid consists of 11.4 million elements while the shrouded rotor domain consists of 12.1 million elements. Various grid details are presented in Figures 7 and 8 .

The ANSYS CFX employs a fully coupled implicit solver to solve the above system of equations. The solution of each set of field equations for each time step consists of two numerically intensive operations, the linearization of the nonlinear equations (assembling of the solution matrix) and the equation solution using an Algebraic Multigrid method.

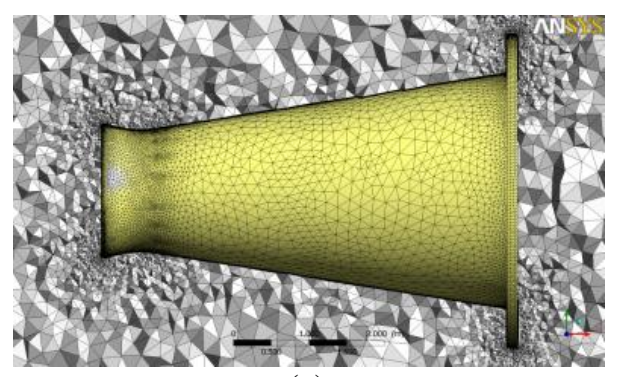

(a)

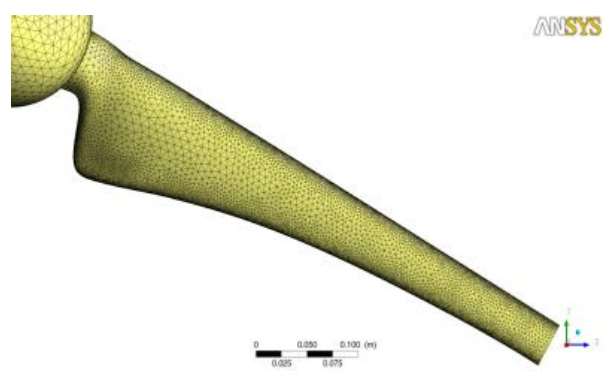

(b)

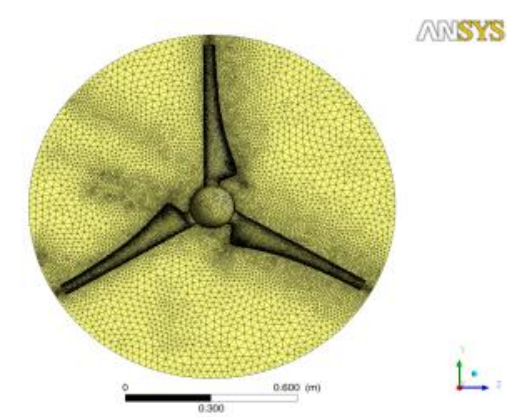

(c)

Figure 7 HAWT computational grid details: a) stationary domain grid, b) blade surface grid c) rotating frame grid 


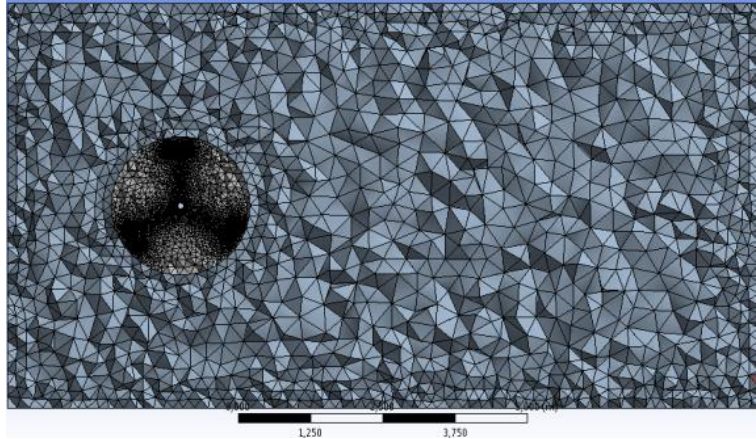

(a)

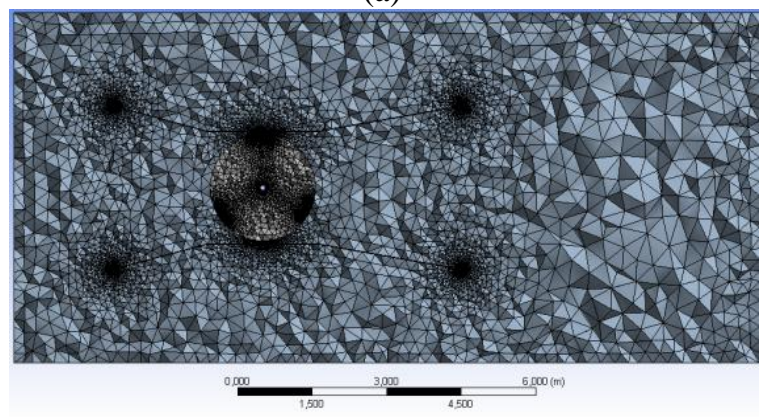

(b)

Figure 8 VAWT computational grid details: a) bare rotor and b) rotor with shroud

\section{Results}

\section{Horizontal Axis Wind Turbine simulations}

Three HAWT cases were analysed. The first case employs a standard diffuser, the second a diffuser with a flange; and, the third a diffuser with a larger flange. The total pressure distribution which corresponds to these cases is shown in Figure 9 and the corresponding velocity magnitude in Figure 10. The presence of the flange is responsible for a large reduction in total pressure and the domain that is influenced increases with the increase in the flange size. The existence of the large recirculation flow structure inside the central part of the diffuser causes the flow to move along the diffuser wall surfaces. This flow pattern is much more pronounced when a flange is employed. The maximum flow vorticity develops inside the diffuser and is due to the shear that develops between the high velocity flow near the walls and the recirculating flow pattern along the diffuser centerline. The vorticity magnitude reduces as the flow discharges from the diffuser. The predicted flow field patterns show similar trends to the experimental results reported by Abe et al. (Abe et al., 2005). However, the results are not identical since the diffuser design parameters between the two works are not the same. Neither the large recirculating area is mentioned by Abe et al. or the significant increase of the flow velocity towards the diffuser walls. The wind turbine rotor of the present study is also different as it was designed independently. Therefore some localised differences in the flow patterns occur and consequently it was not possible to perform a back to back comparison.

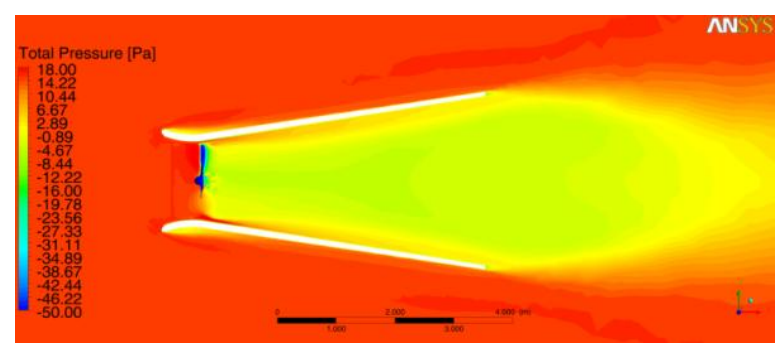

(a)

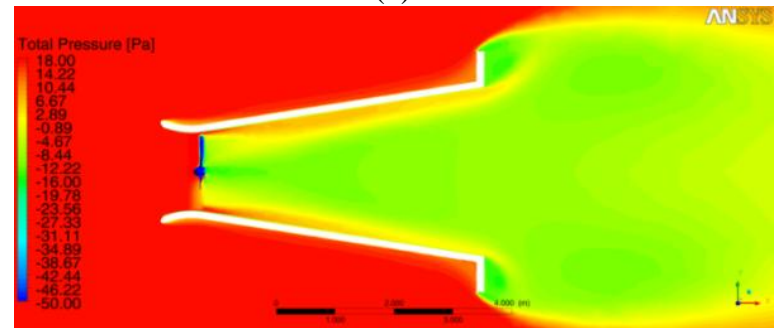

(b)

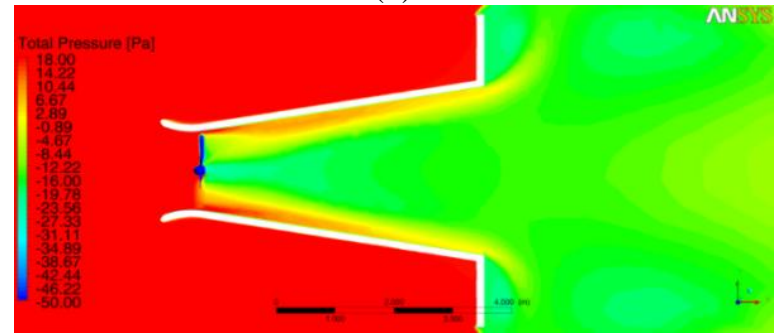

(c)

Figure 9 Total pressure distribution: a) without flange, b) with small flange and c) with large flange

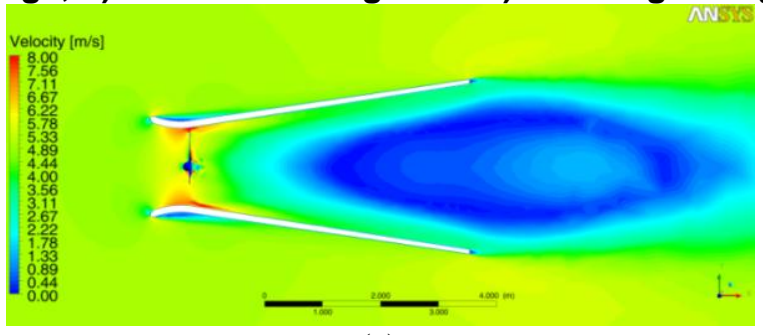

(a)

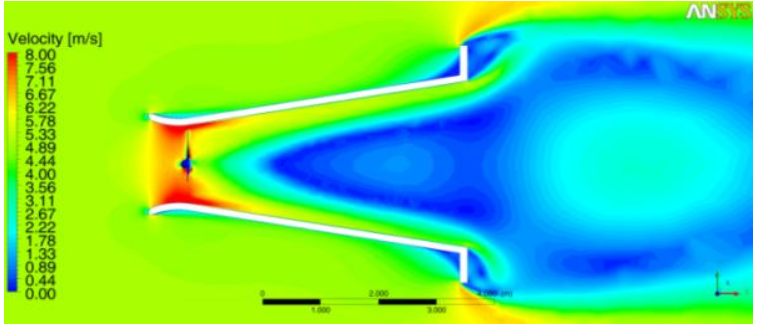

(b)

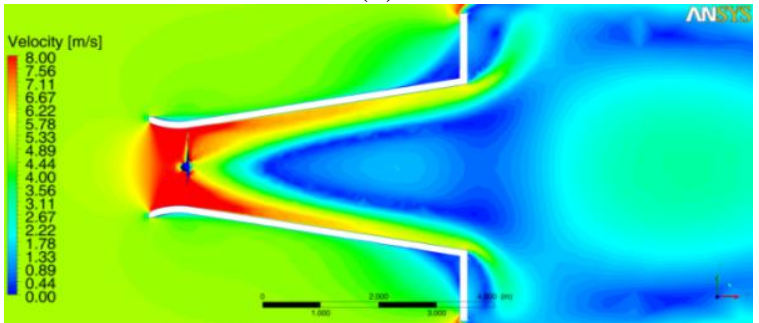

(c)

Figure 10 Velocity magnitude distribution: a) without flange, b) with small flange, c) with large flange 
The calculated power coefficient is presented in Figure 11.a. The presence of the diffuser significantly improves the power output from the turbine rotor. Further improvement is attained through the addition of the flange at the diffuser outlet. The larger flange offers an even better power output result. The power output has been improved by a factor ranging from 2 to 5 as compared to the isolated rotor case. This can be attributed firstly to the higher velocity that approaches the rotor due to the acceleration occurring in the intake and the lower static back pressure at the turbine rotor exit due to the presence of the diffuser. In order to produce the presented curves, three different wind velocities were selected assuming the rotor retains its rotating speed thus providing three discrete values of the TSR. The attained performance characteristics reported by Abe et al. (Abe et al., 2005) are presented in Fig. 11.b. The difference between the current results and the results of Abe et al. are attributed to the different aerodynamic design of the two wind turbine rotors.

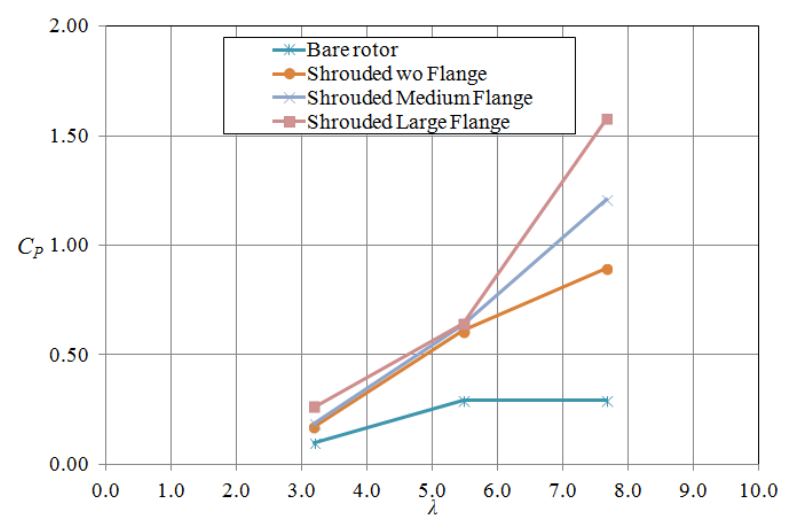

(a)

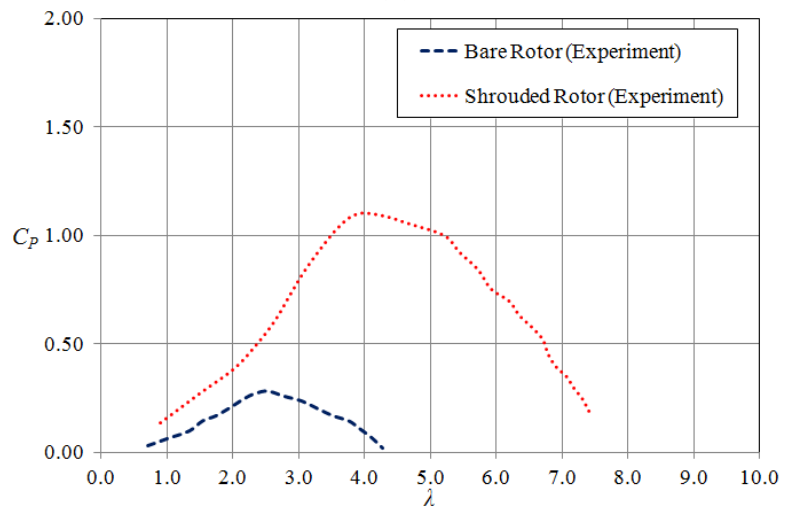

(b)

Figure 11 Power coefficient curves: a) present work and $b$ ) results by Abe et al.

\section{Vertical Axis Wind Turbine simulations}

The computational analysis of the HAWT was carried out for a TSR value of 3 . Figure 12 presents the pressure variation on a horizontal plane at the rotor mid-height. The development of a significant pressure drop occurs inside the shroud. This pressure difference leads more mass flow to pass through the duct.

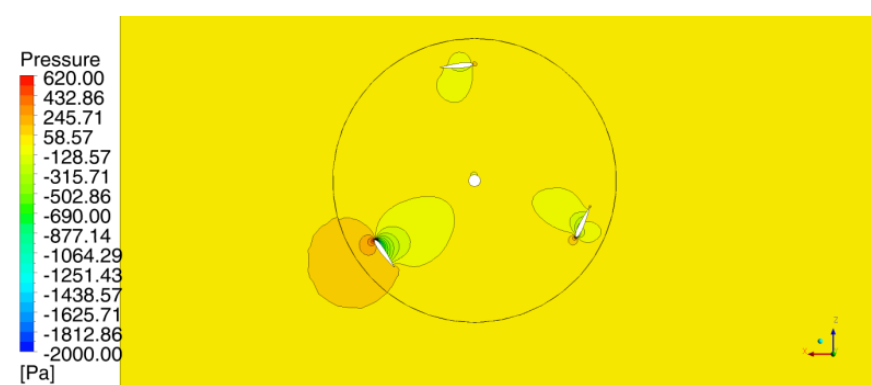

(a)

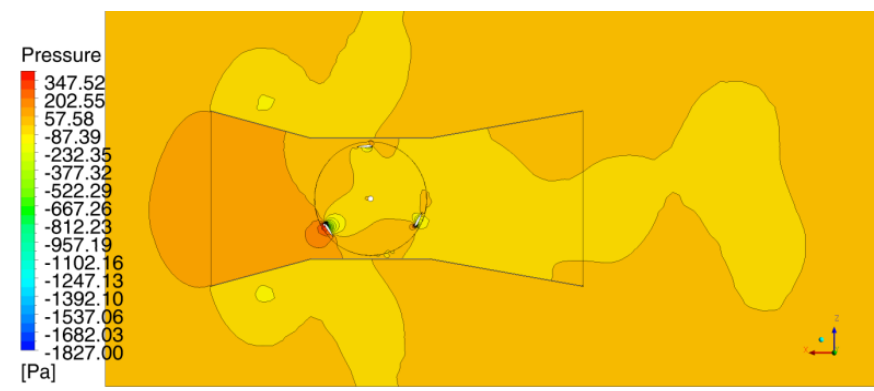

(b)

\section{Figure 12 Pressure contours: a) bare rotor b) shrouded rotor}

The simulation produced detailed results of the pressure distribution on each blade. The integration of the blade pressure over the whole rotor surfaces and their time averaging allows the estimation of pressure forces. Taking into consideration the wall shear stresses it is possible to estimate the total tangential forces acting on the blades and therefore to estimate the rotor torque and power. In Figure 13 , the absolute velocity magnitude is presented.

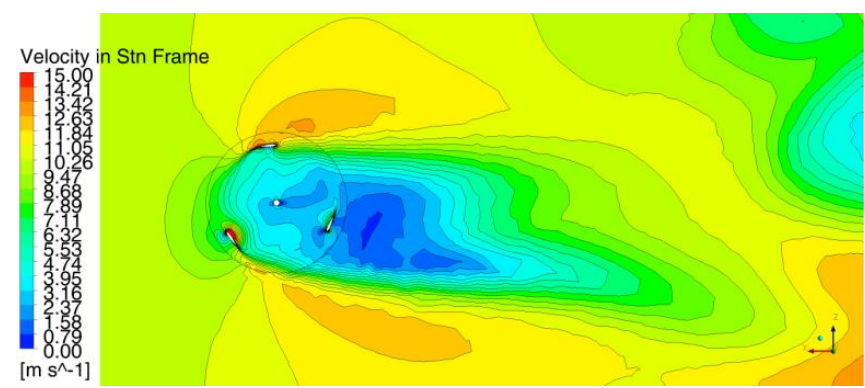

(a)

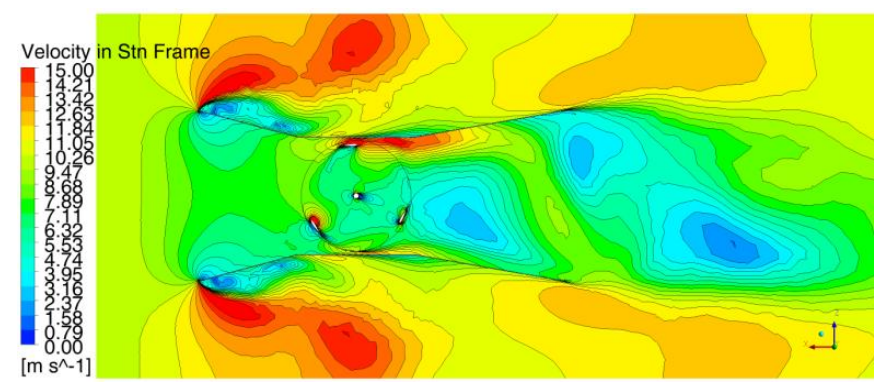

(b)

Figure 13 Velocity contours: a) bare rotor b) shrouded rotor 
The torque curves of both the bare and the shrouded rotor for one rotation at $\mathrm{TSR}=3$ are presented in Fig. 14. It can be seen that the torque is notably increased when the rotor is shrouded. The maximum and minimum torque values are not increased, but the overall torque on each blade and the overall rotor torque are considerably enhanced. A notable characteristic of the torque curves in Fig. 14 is that the shrouded rotor total torque is more uniform over one rotation. This may be attributed to the presence of the shroud effect on the flow. The shroud concentrates and restricts the flow to interact with the rotor more efficiently.
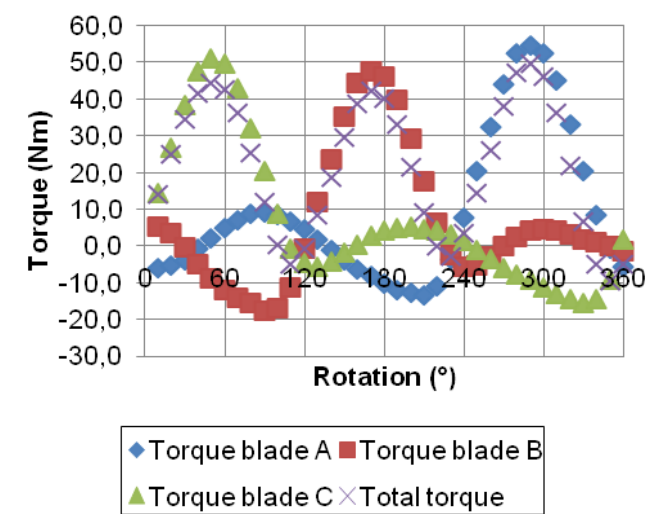

(a)

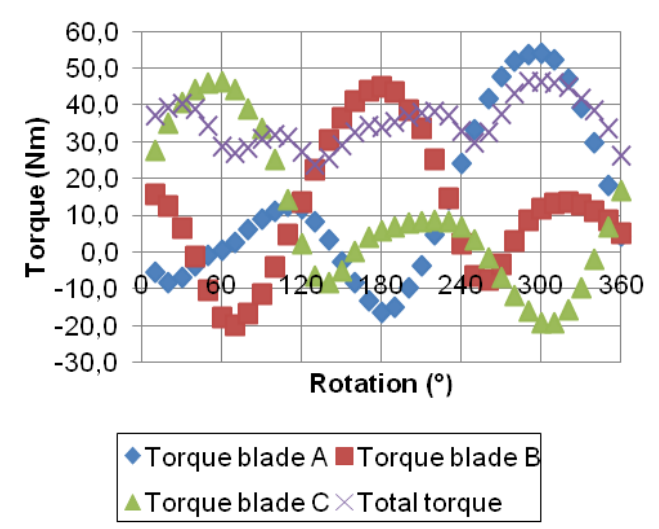

(b)

\section{Figure 14 Torque curves (TSR=3): a) bare rotor} b) shrouded rotor

The calculated power coefficient from both the bare rotor and the shrouded rotor cases is presented in Fig. 15. A dotted line presents the design $\mathrm{C}_{\mathrm{P}}$, calculated using the DMS method. Since the DMS does not take into account the flow separation, turbulence intensity and their effect on rotor performance, it overestimates the expected power. The presence of the diffuser significantly improves the power output from the turbine rotor. The power output has been improved by a factor greater than 2 as compared to the bare rotor case. Specifically, while TSR is 3 the rotor power coefficient approaches to the Betz limit $\left(C_{P}=0.593\right)$. The enhanced rotor performance can be attributed to the higher flow velocity due to the acceleration occurring in the intake and the lower static back pressure at the turbine rotor exit due to the presence of the diffuser. The analysis showed that above a TSR value of 3, the power output of both the bare rotor and the shrouded rotor drops. This may be attributed to both to the off-design operation of the rotor (where it operates with a flow induced velocity beyond the optimal) and the flow detachment on the rotor blades.

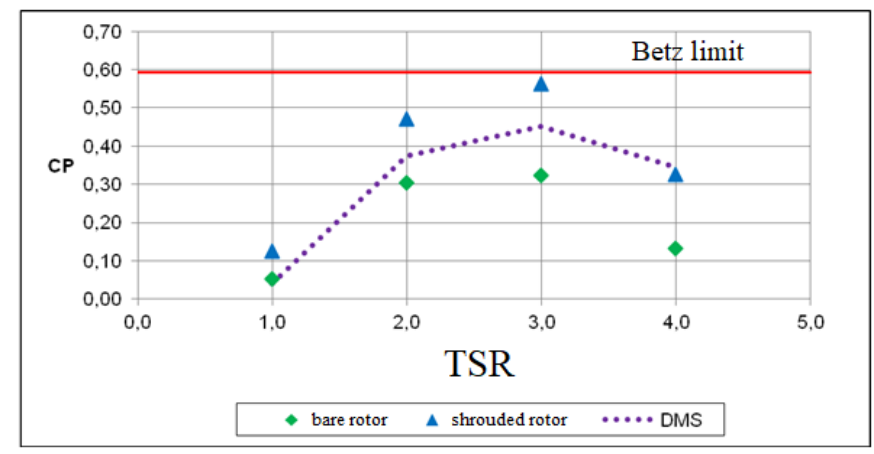

Figure 15 Comparison of power coefficient $C_{p}$ against TSR for the bare rotor and the shrouded rotor simulations

\section{CONCLUSIONS}

A horizontal axis wind turbine and a vertical axis wind turbine and corresponding shrouds were designed and computationally analysed in order to investigate the performance of shrouded wind turbines.

The computational study of shrouds on the performance of a horizontal axis wind turbine has shown that great improvements can be made in terms of power coefficient. The presence of the shroud allows the static pressure drop downwind of the rotor to be reduced, compared to the operation without a shroud, leading to improved energy extraction from the air flow. Adding an exit flange creates a barrier to the flow by forcing air to pass through the shroud. In addition, the presence of the flange causes a greater pressure drop in the back of the shroud, which improves the production of mechanical work by the rotor. Increasing the size of the flange leads to a doubling or even fivefold of the rotor's power coefficient.

Computational aerodynamic study of a vertical axis wind turbine with a shroud has shown that there is a significant improvement in its performance. Betz's limit in this case could not be exceeded, but an improvement in power output was observed. The converging part of the shroud accelerates the flow by inducing a high-speed fluid to the rotor, enhancing its performance. The divergent part of the shell reduces the velocity of the fluid downstream the rotor. The shroud collects the flow and contributes to the development of a more uniform time variation of flow variables during a complete rotation and also produces an increase in torque. The power coefficient of the shrouded wind turbine has been improved by a factor of approximately equal to 2 as compared to the power coefficient of the wind turbine without the shroud. 
In general, it is proven that adding a small wind turbine runner inside a shroud can significantly improve its performance. In particular, the inclusion of wind turbines to a shroud can be very useful when they are to be included in the shell of a building. In the case of building integration, the construction of an additional shroud is not required, since this can result from the building shell itself, thus the cost of construction of the shroud can further be minimized. The only downside to this idea is that the wind turbine loses its ability to operate independently of the wind direction.

\section{NOMENCLATURE}

\section{Abbreviations}

$\begin{array}{ll}\text { BEM } & \text { Blade Element Momentum } \\ \text { CFD } & \text { Computational Fluid Dynamics } \\ \text { DAWT } & \text { Diffuser Augmented Wind Turbine } \\ \text { DMS } & \text { Double-Multiple Streamtube } \\ \text { HAWT } & \text { Horizontal Axis Wind Turbine } \\ \text { NREL } & \text { National Renewable Energy Laboratory } \\ \text { SST } & \text { Shear Stress Transport } \\ \text { VAWT } & \text { Vertical Axis Wind Turbine }\end{array}$

\section{Greek characters}

$\begin{array}{ll}\theta & \text { twist angle }\left(^{\circ}\right) \\ \rho & \text { density }\left(\mathrm{kg} / \mathrm{m}^{3}\right) \\ \tau & \text { shear stress tensor }\left(\mathrm{N} / \mathrm{m}^{2}\right) \\ \Omega & \text { rotational velocity }(\mathrm{rpm})\end{array}$

\section{Latin characters}

$\begin{array}{ll}\mathrm{C}_{\mathrm{p}} & \text { power coefficient }(-) \\ \mathrm{c} & \text { chord length }(\mathrm{m}) \\ \mathrm{p} & \text { Pressure }\left(\mathrm{N} / \mathrm{m}^{2}\right) \\ \mathrm{R} & \text { rotor radius }(\mathrm{m}) \\ \mathrm{r} & \text { any radius }(\mathrm{m}) \\ \mathrm{S} & \text { sink term } \\ \mathrm{TSR} & \text { Tip Speed Ratio }(-) \\ \mathrm{t} & \text { time }(\mathrm{sec}) \\ \mathrm{U} & \text { velocity }(\mathrm{m} / \mathrm{s}) \\ \mathrm{y}^{+} & \text {local Reynolds number }(-)\end{array}$

\section{REFERENCES}

Abe, K., Ohya, Y. (2004). An investigation of flow fields around flanged diffusers using CFD. J. Wind Eng. Ind. Aerodyn., 92(3-4), pp. 315-330.

Abe, K., Nishida, M., Sakurai, A., Ohya, Y., Kihara, H., Wada, E., Sato, K. (2005). Experimental and numerical investigations of flow fields behind a small wind turbine with a flanged diffuser. J. Wind Eng. Ind. Aerodyn., 93(12), pp. 951-970.

Abu-El-Yazied, T. G., Ali, A. M., Montasser, O. A. (2014). Optimization of Wind Duct Geometry for Maximizing Power Generation of Ducted Vertical Turbines. Journal of Engineering, 4(10), pp. 11-19.

Fletcher, C.A.J. (1981). Computational analysis of diffuseraugmented wind turbines. Energy Conv. \& Mgmt, 21(3), pp. 175-183.
Foreman, K.M., Gilbert, B.L., Oman, R.A. (1978). Diffuser augmentation of wind turbines. Solar Energy, 20(4), pp. 305311.

Gilbert, B.L., Foreman, K.M. (1983). Experiments with a diffuser-augmented model wind turbine. Trans. ASME J. Energy Res. Technol., 105(1), pp. 46-53.

Igra, O. (1981). Research and development for shrouded wind turbines. Energy Conv. \& Mgmt., 21(1), pp. 13-48.

Kim, D., Gharib, M. (2013). Efficiency improvement of straight-bladed vertical-axis wind turbines with an upstream deflector. Journal of Wind Engineering and Industrial Aerodynamics, 115, pp. 48-52.

Krishnan, A., Paraschivoiu, M. (2015). 3D Analysis of Building Mounted VAWT with Diffuser Shaped Shroud. Sustainable Cities and Society.

Matsushima, T., Takagi, S., Muroyama, S. (2006). Characteristics of a Highly Efficient Propeller Type Small Wind Turbine With a Diffuser. Renewable Energy, 31(9), pp. 1343-1354.

Menter, F.R. (1994). Two-Equation Eddy-Viscosity Turbulence Models for Engineering Applications. AIAA Journal, 32(8), pp. 1598-1605.

Müller, G., Jentsch, M. F., Stoddart, E. (2009). Vertical axis resistance type wind turbines for use in buildings. Renewable Energy, 34(5), pp. 1407-1412.

Ohya, Y., Karasudani, T., Sakurai, A., Inoue, M. (2006). Development of a High-Performance Wind Turbine Equipped with a Brimmed Diffuser Shroud. Transactions of the Japan Society for Aeronautical and Space Sciences, 49(163), pp. 18-24.

Ohya, Y., Karasudani, T., Sakurai, A., Abe K., Inoue, M. (2008). Development of a Shrouded Wind Turbine With a Flanged Diffuser. Journal of Wind Engineering and Industrial Aerodynamics, 96(5), pp. 524-539.

Ohya, Y., Karasudani, T., 2010, "A Shrouded Wind Turbine Generating High Output Power with Wind-lens Technology", Energies, 3(4), pp. 634-649.

Sharpe, T., Proven, G. (2010). Crossflex Concept and early development of a true building integrated wind turbine. Energy and Buildings, 42(12), pp. 2365-2375.

Somers, D.M. (2005). The S833, S834, and S835 Airfoils: November 2001-November 2002. Airfoils, Inc.

Watson, S. J., Infield, D. G., Barton, J. P., Wylie, S. J. (2007). Modelling of the Performance of a BuildingMounted Ducted Wind Turbine. Journal of Physics: Conference Series, 75.

Zanforlin, S., Letizia, S. (2015). Improving the Performance of Wind Turbines in Urban Environment by Integrating the Action of a Diffuser with the Aerodynamics of the Rooftops. Energy Procedia, 82, pp. 774-781. 